\title{
Hemochromatosis with Mutation of the Ferroportin 1 (IREG1) Gene
}

\author{
Weidong LiU, Souji Shimomura, Hiroyasu ImANishi, Yuna IWAmoto, Naoto IKEDA, \\ Masaki SAITo, Masao OHno, Naoki Hara, Tetsuo YAMAMOTO, \\ Hideji NAKAMURA and Toshikazu HADA
}

\begin{abstract}
The HFE, $H$ ferritin, TFR2, and ferroportin 1 genes of a Japanese patient diagnosed as having hemochromatosis were amplified by PCR and sequenced. A novel mutation in the ferroportin 1 was found in the patient. It was located in the noncoding region of the ferroportin 1; nucleotide 117 adenine was changed to guanine, 7 nucleotides downstream the iron responsive element (IRE) region. This mutation was not found in the patient's son or daughter, or in $\mathbf{5 0}$ healthy individuals. It was suggested that the mutation in the ferroportin 1 may be related to hemochromatosis of this patient. (Internal Medicine 44: 285-289, 2005)
\end{abstract}

Key words: hemochromatosis, ferroportin 1, iron responsive element, siderosis, point mutation.

\section{Introduction}

Hereditary hemochromatosis ( $\mathrm{HH}$ ) is well known to be a genetic heterogeneous disorder. So far, five responsible genes have been identified. The first is located on chromosome $6 \mathrm{p}$, where the HFE gene has been identified. The $\mathrm{C} 282 \mathrm{Y}$ and H63D mutations of the gene have been reported in approximately $90 \%$ of the cases of hemochromatosis in Northern Europe (1). However, according to the previous reports, few cases of Japanese hemochromatosis have these mutations in the HFE gene.

Four other forms of non-HFE hemochromatosis have been reported. These include a juvenile form (2), hemochromatosis associated with the mutant genes in transferrin receptor 2 (TfR2) (3), ferroportin 1 (IREG 1 or MTP 1) (4) and the iron responsive element (IRE) of the ferritin $\mathrm{H}$ subunit
(5). The latter two forms of hemochromatosis are reported to be inherited in an autosomal dominant pattern $(4,5)$. Here, we report a case of hemochromatosis with mutation of the ferroportin 1 gene.

\section{Case Report}

\section{Patient}

A 43-year-old Japanese woman was referred to our hospital because of liver dysfunction. Her father and mother were Japanese. At age 27, she was informed that she had liver disease, but its cause remained unclear. There was no history of alcohol abuse or excessive iron intake. She was administered a blood transfusion at age 27 when she underwent a cesarean section. However, the volume of blood transfused is unclear. There was no known family history of hereditary anemia. Her father died of hepatocellular carcinoma, but the details were unknown. The patient had one son and one daughter, whose serum ferritin levels were 32 and $17 \mathrm{ng} / \mathrm{ml}$, respectively. Figure 1 shows the family tree of the patient.

A physical examination showed mild hepatomegaly and slate-gray pigmentation in the skin. There was no evidence of ascites or hepatic encephalopathy. A 75-g oral glucose tolerance test revealed a pattern of impaired glucose tolerance. Hematological examination revealed no abnormalities: red blood cell count $4.31 \times 10^{12} / l$, hemoglobin $12.9 \mathrm{~g} / \mathrm{dl}$, and hematocrit $41.0 \%$. Liver function tests revealed a mild elevation of aspartate aminotransferase 52 IU/l (normal: 0-35) and alanine aminotransferase $82 \mathrm{IU} / \mathrm{l}$ (normal: 0-35). Total bilirubin was $0.7 \mathrm{mg} / \mathrm{dl}$, albumin $4.7 \mathrm{~g} / \mathrm{dl}$, and prothrombin time $72 \%$. She had elevated serum iron $208 \mu \mathrm{g} / \mathrm{dl}$ (normal: 60-160), serum ferritin 9,660 $\mathrm{ng} / \mathrm{ml}$ (normal: 5-86), and transferrin saturation 92\% (normal 20-45; transferrin saturation was calculated by dividing the serum iron concentration by total serum iron binding capacity). Serological tests for hepatitis $\mathrm{B}$ and $\mathrm{C}$ were negative. Computed tomographic

From Division of Hepatobiliary and Pancreatic Disease, the Department of Internal Medicine, Hyogo College of Medicine, Nishinomiya Received for publication July 1, 2004; Accepted for publication October 25, 2004

Reprint requests should be addressed to Dr. Hiroyasu Imanishi, Division of Hepatobiliary and Pancreatic Disease, the Department of Internal Medicine, Hyogo College of Medicine, 1-1 Mukogawa, Nishinomiya, Hyogo 663-8501 


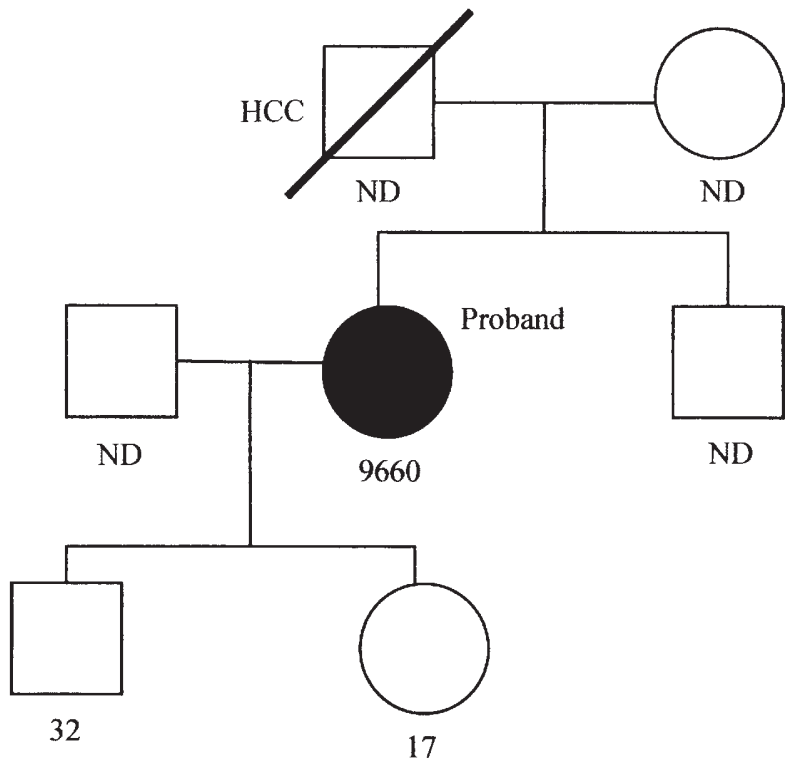

Figure 1. Family pedigree of the patient with hemochromatosis. The black symbol indicates an individual showing the A117G genotype; the number under the symbol indicates the concentration of serum ferritin. ND: not determined.

scans of the abdomen showed increased hepatic and splenic CT density (Fig. 2A). A MRI scan suggested iron accumulation in the liver and spleen (Fig. 2C, 2D). A liver biopsy was performed for diagnostic purposes and the staging of her disease. The specimen obtained by the liver biopsy was prepared with hematoxylin/eosin and Berlin blue staining. Histological examination of the specimen showed chronic hepatitis with massive hepatocellular siderosis: grade 3 [according to the classification of Scheuer et al (6)] as well as iron deposition in the bile duct cells and macrophages (Fig. $3)$.

The patient had been treated with a phlebotomy of $300 \mathrm{ml}$ of blood four times a month for approximately 2 years. Hepatic CT density (Fig. 2B) and iron status improved after the treatment (ferritin: $9,660 \mathrm{ng} / \mathrm{ml}$ to $303 \mathrm{ng} / \mathrm{ml}$; transferrin saturation: $92 \%$ to $23 \%$ ).

\section{Methods}

Informed consent was obtained before taking the blood sample for the HFE, TFR2, ferroportin 1 , and H-ferritin gene analysis. The son and daughter of the patient and 50 healthy individuals were selected for detection of ferroportin 1 mutation.

The genomic DNA extractions, PCR, sequencing methods for $H$-ferritin, TFR2, and ferroportin 1 genes have been reported previously (7). The forward primer for the $H$-ferritin exon 1 is $5^{\prime}$-CCAGACGTTCTTCGCCGAG-3' and the reverse is $5^{\prime}$-GAGCATTCTCAGGGTACA-3', for exon $25^{\prime}$ GGATCCCTAGTATAACACAT- $3^{\prime}$ and $5^{\prime}$-ATACCGAAC ACTGCCAGA-3', for exon 3 5'-AGGTTAGTTGGTAGA
GATGC-3' and 5'-CTAAGGCAAATGATTTCCTC-3', for exon $45^{\prime}$-ATTGGGAAAGCCCACTAAC-3' and 5'-TCAC CCCACGGCTATGGGGAAAT-3', separately. The primers for the TFR2, ferroportin 1, and HFE genes were reported previously $(3,4,8)$.

\section{Results}

From the gene analysis of the four genes, the patient had a mutation in the ferroportin 1 gene (Figs. 4, 5). The mutation is located at the $5^{\prime}$ noncoding region, nucleotide 117 adenine (A) was changed to guanine $(\mathrm{G})$ in the heterozygous pattern. This mutation was not found in the patient's son and daughter, and in 50 healthy individuals.

\section{Discussion}

Ferroportin 1, encoded by IREG1, also called the $S L C 40 A 1$, previously called SLC11A3, is a polytopic transmembrane protein whose structure has not yet been resolved to high resolution $(4,9)$. The autosomal dominant form of $\mathrm{HH}$ and hyperferritinemia has been reported to connect with the mutations in this gene (10-13). These mutations have changed amino acid positions or caused frameshift variants. No mutation in the noncoding region of the gene has been reported yet. The genetic causes of HH in Asians still remains unclear. The mutation in the noncoding region of $\mathrm{H}$-ferritin is responsible for tissue iron deposition in one Japanese $\mathrm{HH}$ family (5). A mutation in the noncoding region of $L$-ferritin has been reported to be related to hyperferritinemia $(10,11)$.

One case, which we reported previously, had a heterozygous A176V mutation in the HFE gene (8). In the present study, we analyzed the HFE, TFR2, ferroportin 1 , and $H$ ferritin genes of a patient with hemochromatosis. The patient has a novel mutation in the ferroportin 1 gene.

The mutation is located at the 117 nucleotide, near the IRE region (nucleotide number from 71 to 110) of the ferroportin 1 gene (Fig. 5). The patient's son and daughter had normal ferritin levels and no mutation. This mutation was not found in 50 normal volunteers and was also not referred to the literature, suggesting that the mutation does not correspond to a polymorphism. Whether this mutation affected the iron regulatory protein (IRP) to connect to IRE of the ferroportin 1 gene, as did the mutation in the $\mathrm{H}$-ferritin IRE region, and caused the tissue iron deposition is not clear. However, from the clinical point of view, in addition to laboratory data as well as image scans, the patient had the typical phenotypic characteristics of hemochromatosis including chronic hepatitis, impaired glucose tolerance, and skin pigmentation. Furthermore, because we were unable to find any abnormalities in the HFE, TFR2, and H-ferritin genes, the possibility remains that the present nucleotide mutation is responsible for an excess iron overload. Since the patient's children had normal serum ferritin levels, the present nucleotide mutation was evidently not transmitted to them.

Early in the course of the disease, most cases with ferroportin 1 mutations have been associated with elevated 

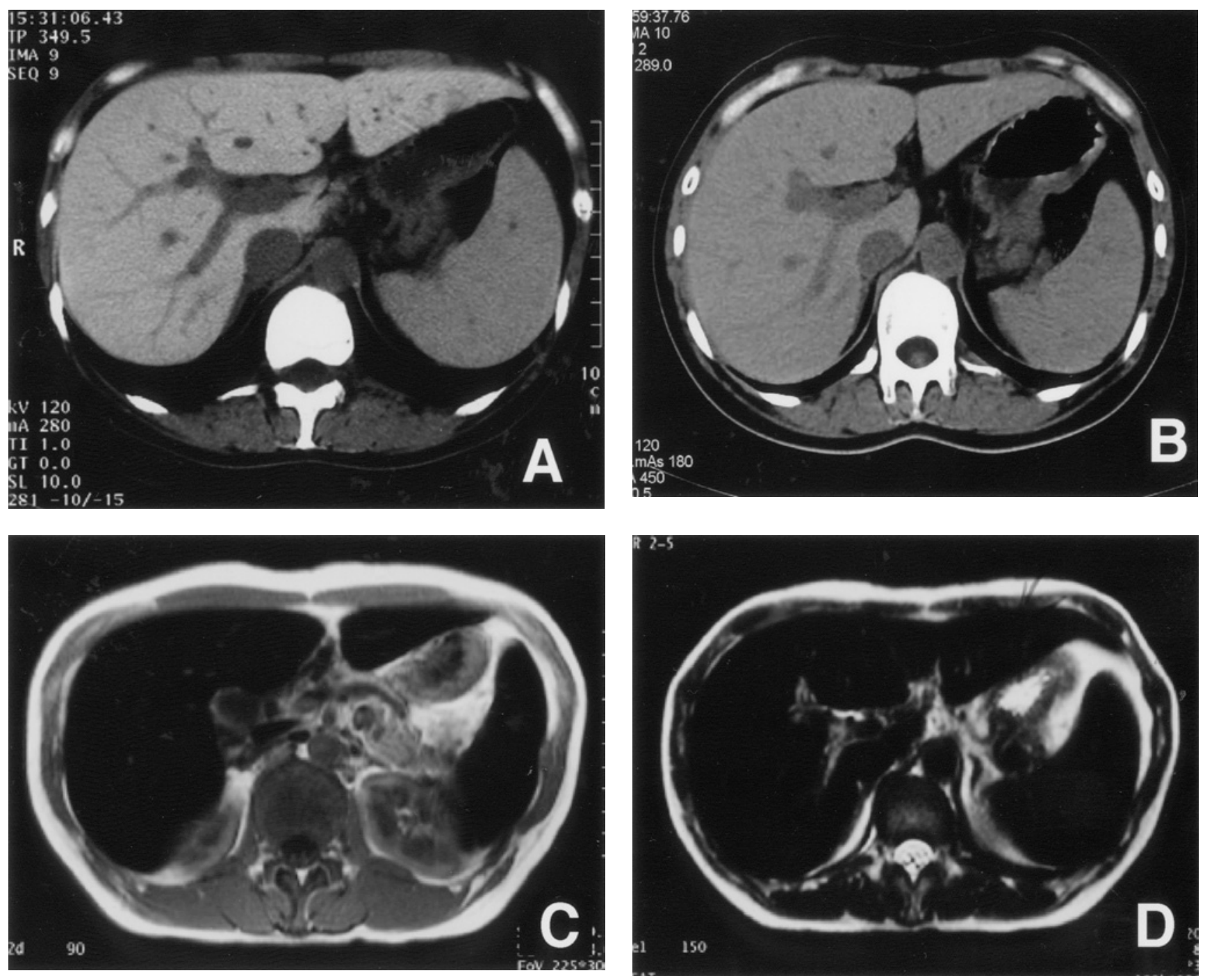

Figure 2. The patient's computed tomography of the abdomen before phlebotomy showed increased hepatic CT number 106 and splenic CT number 80. (A). CT density improved after phlebotomy (B). Magnetic resonance imaging before phlebotomy revealed a low intensity signal in the liver and spleen on both T1- (C) and T2- (D) weighted images.

serum ferritin levels but normal or mildly elevated transferrin saturation (4, 9-11). These individuals have preferential iron deposits in Kupffer cells. Later in the course of disease, transferrin saturations are elevated. These are in contrast to the other types of hemochromatosis. Considering the severity of the disease, high transferrin saturation of the present case is not contradictory to phenotypes of ferroportin 1 mutations. However, the fact that liver histology of our case showed preferential parenchymal iron overload is not consistent with the previous reports if the ferroportin $1 \mathrm{mu}-$ tation in our case caused hemochromatosis. Recently, Wallace et al reported a mutation in ferroportin $l$ in an Australian family associated with high transferrin saturation and parenchymal iron loading in one member of the family (14). The possibility that ferroportin 1 mutations cause wide spectrum of phenotypes including our case is considered.
Some authors suggest that a gain-of-function mutation of ferroportin 1 might augment transfer of iron from the enterocytes to the circulation (4), others suggest that a lossof-function mutation could cause a impairment of iron recycling by macrophages (15). However, whether the mutation in the noncoding region of ferroportin 1 in our case is a gainof-function mutation or a loss-of-function mutation is not clear. From the clinical and pathological findings, we suggest that the mutation is a gain-of-function mutation if the mutation caused the hemochromatosis.

Recently, a mutation G490D in the ferroportin 1 gene has been reported to be responsible for $\mathrm{HH}$ in an Asian proband (9). This indicates that the ferroportin 1 mutation in Asians is also related to HH. Further study is needed to clarify the actual significance in the nucleotide mutation found in the present case. 


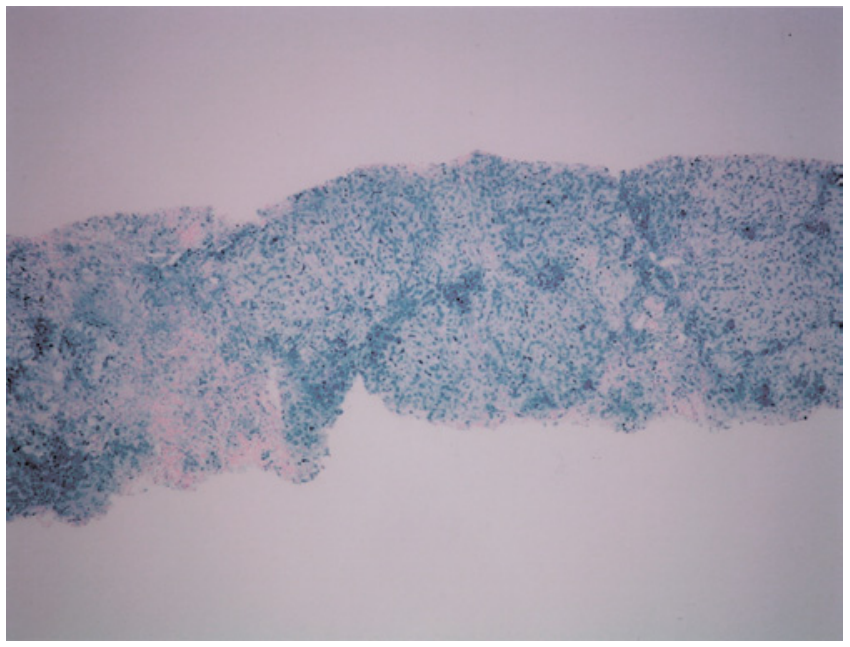

A

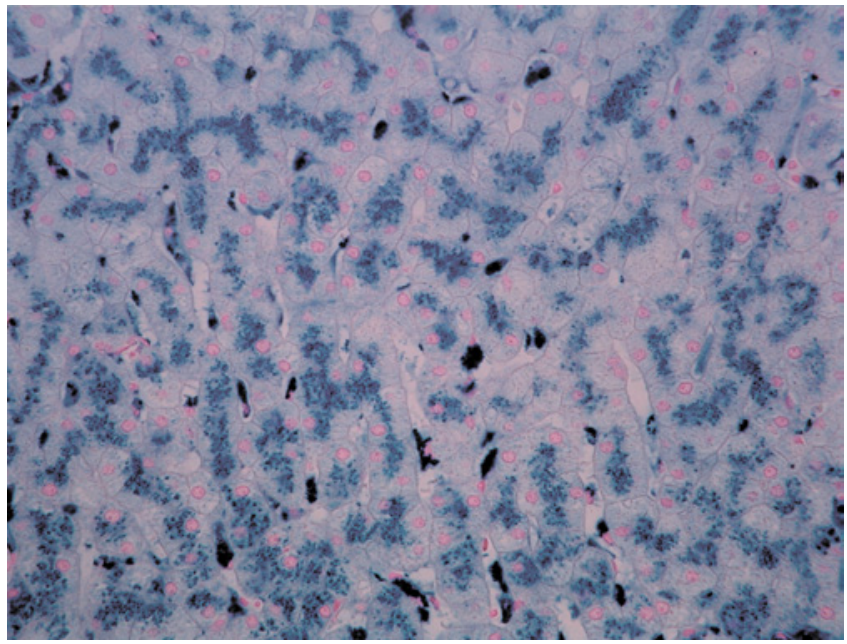

B

Figure 3. Berlin blue stain of the liver showed iron overload, located both in hepatocytes (grade 3), and Kupffer cells. The hepatocytes with diffuse iron deposits in the liver biopsy section were seen $(A: \times 40 ; B: \times 200)$.

$117 \mathrm{~A}: \mathrm{A}+\mathrm{G}$

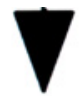

O A M A AA A AOA AA AT

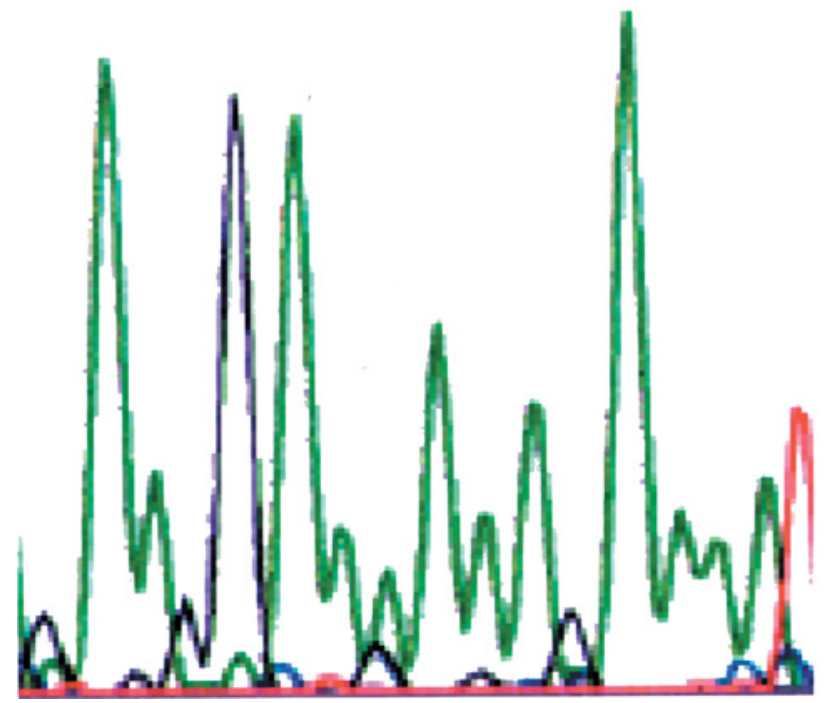

A: forward
$117 \mathrm{~T}: \mathrm{C}+\mathrm{T}$
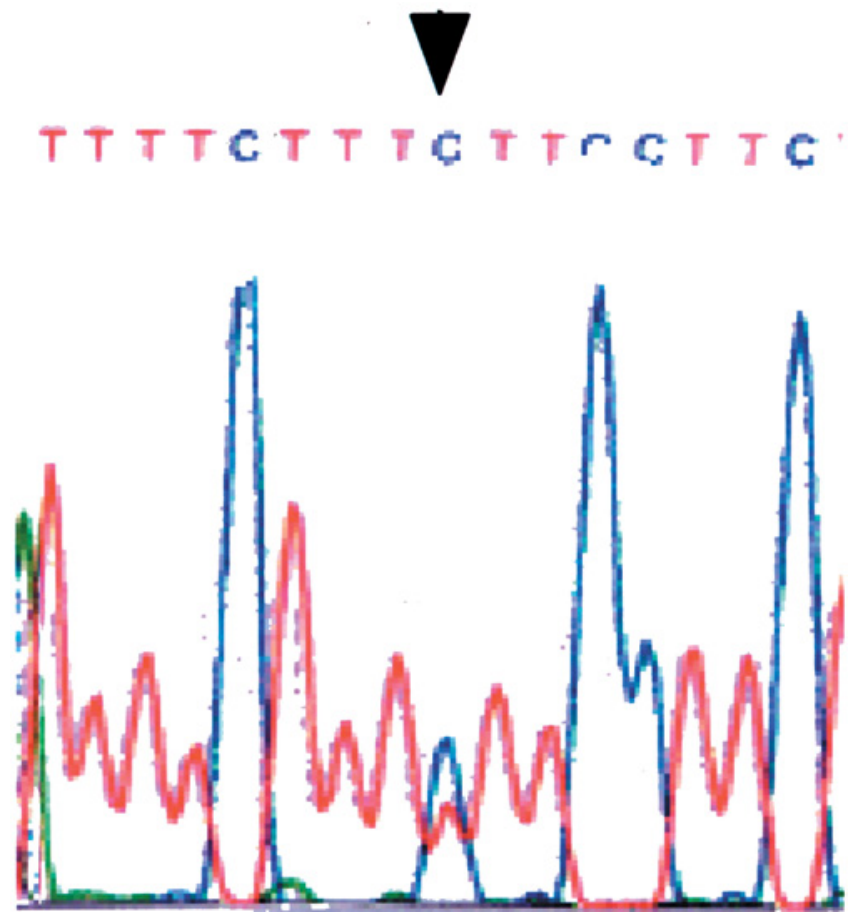

B: reverse

Figure 4. Sequence map of the A117G mutation found in the ferroportin 1 gene from the patient. A: Forward sequence, nucleotide $117 \mathrm{~A} \rightarrow \mathrm{A}+\mathrm{G}$. B: Reverse sequence nucleotide $117 \mathrm{~T} \rightarrow \mathrm{C}+\mathrm{T}$. 


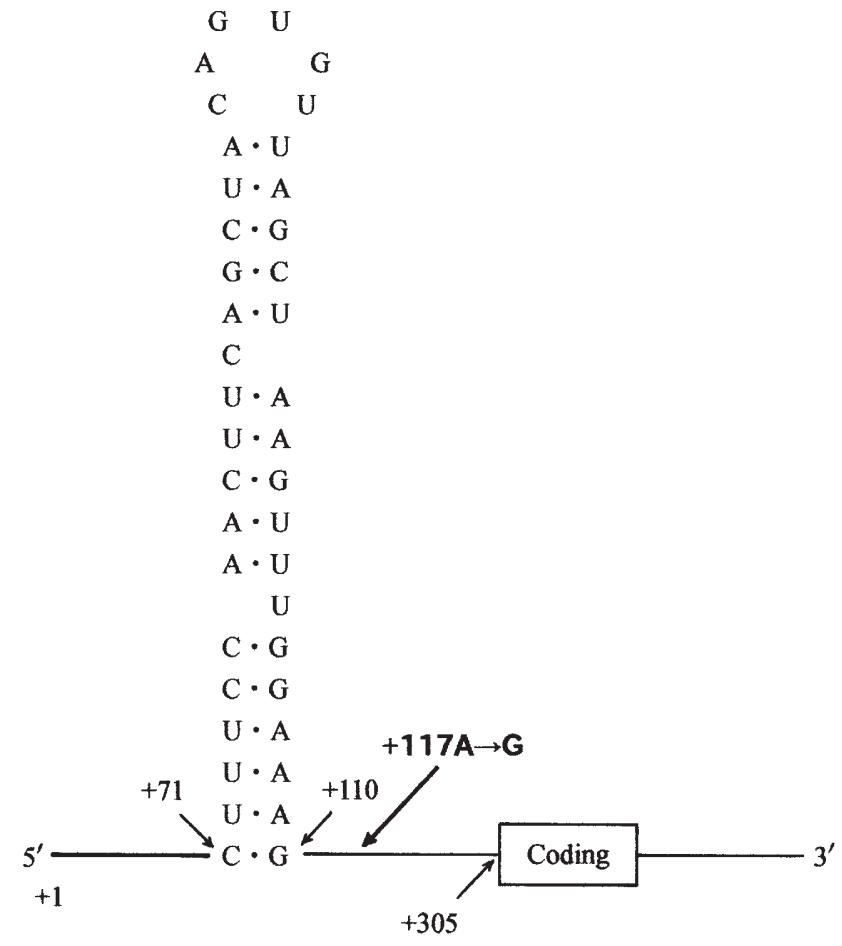

Figure 5. Predicted secondary structure in the 5' UTR of the ferroportin 1 RNA.

\section{References}

1) Feder JN, Gnirke A, Thomas W, et al. A novel MHC class I-like gene is mutated in patients with hereditary haemochromatosis. Nat Genet 13: 399-408, 1996.

2) Roetto A, Totaro A, Cazzola M, et al. Juvenile hemochromatosis locus maps to chromosome 1q. Am J Hum Genet 64: 1388-1393, 1999.
3) Camaschella C, Roetto A, Cali A, et al. The gene TFR2 is mutated in a new type of haemochromatosis mapping to 7q22. Nat Genet 25: 14$15,2000$.

4) Njajou OT, Vaessen N, Joosse M, et al. A mutation in SLC11A3 is associated with autosomal dominant hemochromatosis. Nat Genet $\mathbf{2 8}$ : 213-214, 2001.

5) Kato J, Fujikawa K, Kanda M, et al. A mutation in the iron-response element of $\mathrm{H}$ ferritin mRNA, causing autosomal dominant iron overload. Am J Hum Genet 69: 191-197, 2001.

6) Scheuer PJ, Williams R, Muir AR. Hepatic pathology in relatives of patients with hemochromatosis. J Pathol Bacteriol 84: 53-64, 1962.

7) Liu W, Hada T, Fukui K, et al. Familial hypocholinesterasemia found in a family and a new confirmed mutation. Intern Med 36: 9-13, 1997.

8) Imanishi H, Liu W, Cheng J, Ikeda N, Amuro Y, Hada T. Idiopathic hemochromatosis with the mutation of Ala176Val heterozygous for HFE gene. Intern Med 40: 479-483, 2001.

9) Jouanolle AM, Douabin-Gicquel V, Halimi C, et al. Novel mutation in ferroportin 1 gene is associated with autosomal dominant iron overload. J Hepatol 39: 286-289, 2003.

10) Hetet G, Devaux I, Soufir N, Grandchamp B, Beaumont C. Molecular analyses of patients with hyperferritinemia and normal serum iron values reveal both $\mathrm{L}$ ferritin IRE and 3 new ferroportin (slc11A3) mutations. Blood 102: 1904-1910, 2003.

11) Cazzola M, Cremonesi L, Papaioannou M, et al. Genetic hyperferritinaemia and reticuloendothelial iron overload associated with a three base pair deletion in the coding region of the ferroportin gene (SLC11A3). Br J Haematol 119: 539-546, 2002.

12) Devalia V, Carter K, Walker AP, et al. Autosomal dominant reticuloendothelial iron overload associated with a 3-base pair deletion in the ferroportin 1 gene (SLC11A3). Blood 100: 695-697, 2002.

13) Rivard SR, Lanzara C, Grimard D, et al. Autosomal dominant reticuloendothelial iron overload (HFE type 4) due to a new missense mutation in the FERROPORTIN 1 gene (SLC11A3) in a large FrenchCanadian family. Haematologica 88: 824-826, 2003.

14) Wallace DF, Clark RM, Harley HA, Subramaniam VN. Autosomal dominant iron overload due to a novel mutation of ferroportin 1 associated with parenchymal iron loading and cirrhosis. J Hepatol 40: 710713, 2004.

15) Montosi G, Donovan A, Totaro A, et al. Autosomal-dominant hemochromatosis is associated with a mutation in the ferroportin (SLC11A3) gene. J Clin Invest 108: 619-623, 2001. 